
\title{
25 Research Soure \\ Effect of insect feces (Hermetia illucens) on rice growth and heavy metal migration from polluted soil to rice plant
}

\section{Xiaobo Wang}

Tianjin Agricultural University

\section{Nan Wu}

Tianjin Agricultural University

\section{Xiang Wu}

Tianjin Agricultural University

\section{Weina Geng}

Tianjin Agricultural University

Xiaoyan Xu ( $\nabla$ xuxy6699@163.com )

Tianjin Agricultural University

\section{Research Article}

Keywords: Black soldier fly, Larval feces, Rice, Heavy metals, Migration, Accumulation

Posted Date: June 3rd, 2021

DOl: https://doi.org/10.21203/rs.3.rs-188877/v1

License: (c) (i) This work is licensed under a Creative Commons Attribution 4.0 International License. Read Full License

Version of Record: A version of this preprint was published at Environmental Science and Pollution Research on October 6th, 2021. See the published version at https://doi.org/10.1007/s11356-021-168030 . 


\section{Abstract}

Insect feces are a new kind of biological organic fertilizer. Little is known about the influences of insect feces on rice growth and heavy metal migration from soil to rice plant. In this study, the effects of different amounts (CK (0\%), T1 (2\%), T2 (4\%), T3 (6\%), and T4 (8\%) ) of black soldier fly larvae (BSFL) feces on the rice growth and the migration/accumulation of heavy metals ( $\mathrm{Cd}$ and $\mathrm{Pb}$ ) were investigated by pot experiments within two years. The application of insect feces remarkably increased the contents of soil $\mathrm{pH}$, organic matter, ammonium nitrogen, available phosphorus and potassium. Meanwhile, the insect feces application reduced the weak acid soluble contents of soil $\mathrm{Cd}$ and $\mathrm{Pb}$ by $8.3-56.8 \%$, but increased those in the oxidizable (by 22.4-165.7\%) and residual (by 1.8-225.6\%) states. Except for the T4 treatment in the first year, all fertilization treatments increased the rice yield (up to $43.7 \%$ and $195.5 \%$ higher than those of $\mathrm{CK}$ within two years). Moreover, the insect feces application reduced the contents of $\mathrm{Cd}(8.3 \%-66.7 \%)$ and $\mathrm{Pb}(6.4 \%-61.8 \%)$ in different parts of rice. Under the same treatment, the metal contents in each part of rice in the second year were lower than those in the first year. The insect feces application decreased the absorption coefficients (24.4\%-57.5\%) and secondary transport coefficients (3.6\%-44.1\%) of $\mathrm{Cd}$ and $\mathrm{Pb}$ by rice plant.

\section{Introduction}

The cultivated land area polluted by heavy metals in China is about 20 million $\mathrm{km}^{2}$, due to the massive discharge of industrial "Three Wastes", sewage irrigation and unreasonable use of pesticides and fertilizers. Every year, more than 12 million tons of grain is reduced due to pollution, resulting in a total economic loss of at least 20 billion yuan (Chen 2018; Chen et al. 2018). What is more serious is that soil heavy metals will migrate into plants as plants grow (Wang et al. 2019). These metals may eventually enter human bodies through food chain and pose a hazard to human health (Li et al. 2020a).

Among the numerous soil heavy metal remediation technologies, the application of organic fertilizers to passivate metal activities has been widely used to reduce the metal harm to crops due to the advantages of low cost and simple implementation (Fellet et al. 2011; Meng et al. 2018; Tang et al. 2015). Organic matters in organic fertilizers contain a large number of functional groups and have a strong adsorption capacity for heavy metal ions (Tian et al. 2012). Humic acid produced by humics decomposition can form complexes with heavy metal ions to fix metal ions, thereby reducing the bioavailability of heavy metals and their toxic effects on crops (Udovic and McBride 2012). At the same time, organic fertilizers can increase soil fertility and promote crop growth.

The feces of black soldier fly larvae (BSFL) are a new type of organic fertilizer, which are gray-brown, granular and odorless. Organic fertilizers of BSFL feces contain abundant organic matters and beneficial microbial population (Liu et al. 2019a; Newton et al. 2005). Studies have found that the feces of BSFL fed with pig manure met the standard of organic fertilizers, and the growth quality of cabbage could be improved after applying the BSFL feces (Li et al. 2016). Wu et al. (2019) found that the application of BSFL feces increased the yield of tomato. However, to our best knowledge, the influence of BSFL feces on 
the rice growth and the migration/accumulation of soil heavy metals has not been reported, as well as the metal morphology changes. Thus, the present study is intended to investigate the effects of insect feces on the soil properties, soil heavy metal morphology changes, rice growth and metal migration from polluted soil to rice plant.

\section{Materials And Methods}

\subsection{Experimental materials}

The rice variety used for experiments was Tianjin Jinyuan E28. Soil was taken from a paddy field in Hubei Province, China. The basic physicochemical properties of soil were as follows: pH 6.24, EC $415 \mu \mathrm{s}$ $\mathrm{cm}^{-1}$, ammonium nitrogen $70.12 \mathrm{mg} \mathrm{kg}^{-1}$, available phosphorus $12.23 \mathrm{mg} \mathrm{kg}^{-1}$, available potassium $157.68 \mathrm{mg} \mathrm{kg}^{-1}$, organic matter (OM) 6.52\%, Cd $10.62 \mathrm{mg} \mathrm{kg}^{-1}, \mathrm{~Pb} 1371.36 \mathrm{mg} \mathrm{kg}^{-1}, \mathrm{Cu} 151.37 \mathrm{mg} \mathrm{kg}^{-1}$ and $\mathrm{Cr} 182.02 \mathrm{mg} \mathrm{kg}^{-1}$. The paddy soil was air-dried, grounded to pass through a 18-mesh sieve and then mixed thoroughly. Because $\mathrm{Cd}$ and $\mathrm{Pb}$ in the paddy soil exceeded the Chinese soil environmental quality risk control standard for soil contamination of agricultural land (trial) (GB 15618 -2018), the present study focused on the impact of insect feces on the migration of these two heavy metals.

The insect feces were obtained after the bio-transformation process of chicken manure by BSFL. The basic physicochemical properties of insect feces were as follows: $\mathrm{pH} \mathrm{8.3,} \mathrm{OM} \mathrm{64.0 \% ,} \mathrm{total} \mathrm{nitrogen} \mathrm{(TN)}$

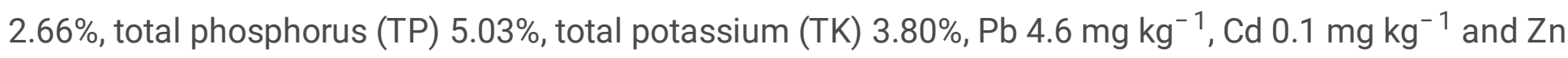
$46 \mathrm{mg} \mathrm{kg}^{-1}$.

\subsection{Experimental setup}

A total of five treatments were carried out by adding different amounts of insect feces into soil, namely CK (0\%), T1 (2\%), T2 (4\%), T3 (6\%) and T4 (8\%). Each treatment was repeated for 3 times. For each replicate, a clean plastic bucket ( $35 \mathrm{~cm}$ in diameter, $27 \mathrm{~cm}$ in height) was filled with $10 \mathrm{~kg}$ of air-dried soil which was well stirred with insect feces. After adding water, the plastic bucket was kept in the shade for one month. On May 2018, the uniform rice seedlings were selected and transplanted into buckets with 4 seedlings per bucket. The plastic buckets were randomly arranged in the greenhouse of Tianjin Agricultural University. During the whole growth period, the seedlings were routinely managed and were kept under flooding condition with a $3-5 \mathrm{~cm}$ water layer above the soil surface. The rice plants were harvested on October 2018. In 2019, another rice cultivation experiment was carried out on the basis of the previous experiment. No chemical fertilizers were used during the whole rice growing period, and the same operation was maintained.

\subsection{Determination methods}

Soil samples taken from the bucket were air-dried and grounded to pass through 18-mesh and 65-mesh sieves, respectively. Soil pH, OM and electrical conductivity (EC) were determined according to our previous study (Wang et al. 2020). Ammonium nitrogen was determined by indophenol-blue colorimetry 
method. Available phosphorus was determined by molybdenum blue colorimetry and available potassium was determined by flame photometer method (Bao 2000). The modified BCR morphological method was used to determine the contents of heavy metals $\mathrm{Cd}$ and $\mathrm{Pb}$ in various forms in the soil, as described in our previous study (Wang et al. 2020). Briefly, four metal forms were extracted and determined by ICP-MS (iCAPQ, Thermo Scientific, USA), including weak acid soluble fraction (F1), reducible fraction (F2), oxidizable fraction (F3) and residual fraction (F4).

The harvested rice plants were oven-dried at $105^{\circ} \mathrm{C}$ for $30 \mathrm{~min}$ and baked at $70{ }^{\circ} \mathrm{C}$ to constant weight. Then the rice yield and heavy metal contents of different parts were determined. $0.5 \mathrm{~g}$ of the crushed rice plant samples of different parts (grain, husk, leaf, stem and root) were digested by adding $6 \mathrm{~mL} \mathrm{HNO}_{3}$, $2 \mathrm{~mL} \mathrm{HCl}$ and $2 \mathrm{~mL} \mathrm{H}_{2} \mathrm{O}_{2}$ in a microwave digestion apparatus (CEM-MARS 6S USA). The digested solution was then determined by ICP-MS (iCAPQ, Thermo Scientific, USA) for metal analysis.

\subsection{Data processing}

The calculation and plot drawing of data were completed by Excel 2010, and the significance difference analysis $(P<0.05)$ was completed by SPSS 17.0. The absorption and transport coefficients of heavy metals were calculated according to the following equations (Carbonell-Barrachina et al. 1997; Zhang et al. 2020):

Absorption coefficients = heavy metal concentration in roots $/$ heavy metal concentration in soil; (1)

Primary transport coefficients = heavy metal concentration in stem and leaf $/$ heavy metal concentration in root system; (2)

Secondary transport coefficients = heavy metal concentration in grain / heavy metal concentration in stem and leaf. (3)

\section{Results}

\subsection{Effects of different amounts of insect feces on soil physicochemical properties}

The application of insect feces as organic fertilizers increased soil $\mathrm{pH}$ and the contents of $\mathrm{OM}$ and EC (Fig. 1). This growing tendency was more evident with the increase in the amounts of insect feces applied. For example, soil pH increased from 6.46 (CK) to 7.13 (T4 treatment) in 2018 and from 6.51 (CK) to 7.14 (T4 treatment) in 2019. Meanwhile, the OM contents under T4 treatment were increased by $25.3 \%$ and $32.5 \%$ in the two years, respectively, compared with the control. On the other hand, the contents of ammonium nitrogen, available phosphorus and available potassium in the soil obviously elevated with the increase of the application amounts of insect feces (Fig. 1). The contents of ammonium nitrogen, available phosphorus and available potassium under T4 treatment were the highest, which were increased by $195.4 \%, 288.2 \%$ and $1869.7 \%$ in 2018 and $90.2 \%, 312.0 \%$ and $2014.5 \%$ in 2019 , respectively, 
compared with the control. Due to the nutrients absorption for rice growth, the contents of various soil nutrients in 2019 reduced than those in 2018. For example, the contents of ammonium nitrogen, available phosphorus and available potassium in the second year were decreased by $6.6 \%-29.7 \%, 27.6 \%-34.5 \%$ and $29.1 \%-61.0 \%$, respectively, compared with those in the first year.

\subsection{Effects of insect feces on $\mathrm{Cd}$ and $\mathrm{Pb}$ morphological changes in soil}

The concentrations of $\mathrm{Cd}$ and $\mathrm{Pb}$ in soil after application of insect feces are shown in Table 1. No significant difference was observed in metal concentrations under different treatments. Meanwhile, for the same heavy metal, there was no significant difference in the concentration between two years. Figure 2 reveals the distribution percentage of different $\mathrm{Cd}$ speciation in soil before and after application of insect feces. Cd mainly existed as weak acid soluble state (F1) in soil (44.2-69.8\%) no matter whether the soil was fertilized or not. After the application of insect feces in 2018, the weak acid soluble fraction of $\mathrm{Cd}$ was reduced by $8.3 \%-24.2 \%$ compared with $\mathrm{CK}$, while the percentages of reducible (F2), oxidizable (F3) and residual (F4) states of $\mathrm{Cd}$ in fertilized soil were enhanced by $2.2 \%-10.0 \%, 52.4 \%-165.7 \%$ and 46.9\%-118.6\%, respectively. In 2019, the weak acid soluble state of $\mathrm{Cd}$ in fertilized soil was reduced by $18.0 \%-33.4 \%$ than $\mathrm{CK}$, while the percentages of reducible, oxidizable and residual states of Cd in fertilized soil were increased by $0.6 \%-7.8 \%, 52.7 \%-99.2 \%$ and $135.3 \%-225.6 \%$, respectively. Compared with 2018 , the weak acid soluble state of $\mathrm{Cd}$ in 2019 diminished by $5.0 \%-17.7 \%$ but the oxidizable state increased by $47.5 \%-96.9 \%$. In both of the two years, the ratio of weak acid-soluble Cd under T4 treatment was the lowest, while the contents of oxidizable and residual $\mathrm{Cd}$ were the highest.

Table 1

Concentrations of $\mathrm{Cd}$ and $\mathrm{Pb}$ in soil before and after application of insect feces

\begin{tabular}{|lllll|}
\hline Treatment & Cd & \multicolumn{3}{c|}{ Pb } \\
\cline { 2 - 5 } & $\mathbf{2 0 1 8}$ & $\mathbf{2 0 1 9}$ & $\mathbf{2 0 1 8}$ & $\mathbf{2 0 1 9}$ \\
\hline CK & $10.85 \pm 0.34 \mathrm{a}$ & $10.70 \pm 0.31 \mathrm{a}$ & $1346.15 \pm 34.5 \mathrm{a}$ & $1333.46 \pm 44.3 \mathrm{a}$ \\
\hline T1 & $10.75 \pm 0.21 \mathrm{a}$ & $10.90 \pm 0.34 \mathrm{a}$ & $1330.31 \pm 33.2 \mathrm{a}$ & $1320.70 \pm 34.3 \mathrm{a}$ \\
\hline T2 & $10.69 \pm 0.32 \mathrm{a}$ & $10.80 \pm 0.23 \mathrm{a}$ & $1328.27 \pm 46.3 \mathrm{a}$ & $1323.83 \pm 48.2 \mathrm{a}$ \\
\hline T3 & $10.55 \pm 0.24 \mathrm{a}$ & $10.70 \pm 0.26 \mathrm{a}$ & $1320.21 \pm 38.3 \mathrm{a}$ & $1319.93 \pm 43.1 \mathrm{a}$ \\
\hline T4 & $10.65 \pm 0.21 \mathrm{a}$ & $10.80 \pm 0.24 \mathrm{a}$ & $1329.67 \pm 26.8 \mathrm{a}$ & $1324.14 \pm 32.3 \mathrm{a}$ \\
\hline
\end{tabular}

As shown in Fig. 3, Pb mainly existed in the reducible state (65.5\%-70.3\%) in soil. After the application of insect feces in 2018 , the proportion of weak acid soluble Pb decreased by $17.4 \%-54.1 \%$ compared with $\mathrm{CK}$, while the percentages of reducible, oxidizable and residual $\mathrm{Pb}$ in fertilized soil were increased by $1.7 \%-2.8 \%, 22.4 \%-78.0 \%$ and $1.8 \%-14.7 \%$, respectively. In 2019 , the proportion of weak acid soluble $\mathrm{Pb}$ in fertilized soil was reduced by $22.2 \%-56.8 \%$ than $\mathrm{CK}$, while the percentages of oxidizable and residual $\mathrm{Pb}$ in fertilized soil were increased by $40.0 \%-66.6 \%$ and $9.3 \%-18.7 \%$, respectively. For reducible $\mathrm{Pb}$, their proportions in fertilized soil in 2019 generally increased by $0.19 \%-1.66 \%$ than those in CK, except for T1 
treatment (slightly decreased by 0.83\%). Compared with 2018, the oxidizable and residual Pb in 2019 increased by $12.1 \%-49.3 \%$ and $9.1 \%-19.3 \%$, respectively. In both of the two years, the ratio of weak acidsoluble $\mathrm{Pb}$ under $\mathrm{T} 4$ treatment was the lowest, while the contents of reducible, oxidizable and residual $\mathrm{Cd}$ were the highest. Totally, the application of insect feces fertilizers reduced the bioavailability of $\mathrm{Cd}$ and $\mathrm{Pb}$ in the paddy soil.

\subsection{Effects of insect feces on rice yield}

In 2018 , the rice yield under T2 treatment was the highest $\left(36.0 \mathrm{~g} \mathrm{pot}^{-1}\right)$, which was $43.7 \%$ higher than that of CK, followed by T1 and T3 treatment (increased by $28.0 \%$ and $19.9 \%$, respectively) (Fig. 4). On the contrary, the rice yield of T4 treatment was the lowest, which was reduced by $20.0 \%$ compared with CK. In 2019 , the order of rice yield under different treatments was T4 $>\mathrm{T} 3>\mathrm{T} 2>\mathrm{T} 1>\mathrm{CK}$, and the output of T4 treatment was $63.2 \mathrm{~g} \mathrm{pot}^{-1}$, which was enhanced by $195.5 \%$ than that of CK. Compared with 2018 , the rice yield of T3 and T4 treatments in 2019 increased by $85.3 \%$ and $214.7 \%$, respectively; while the rice yield of CK and T1 treatment decreased by $14.7 \%$ and $10.8 \%$, respectively. There was no significant difference in the yield under T2 treatment between two years. This suggested that the amount of fertilizer applied under T2 treatment in 2018 was reasonable, but the amounts under T3 and T4 treatments were excessive. In 2019, the amount of fertilizer applied under T4 treatment was reasonable. The results indicated that the effect of high amount of insect feces fertilizers was more obvious with the extension of time

\subsection{Effects of insect feces on $\mathrm{Cd}$ and $\mathrm{Pb}$ contents in various parts of rice plant}

As seen in Fig. 5, the application of insect feces as organic fertilizers reduced the contents of $\mathrm{Cd}$ in various parts of rice plant. For CK treatment, the contents of $\mathrm{Cd}$ in rice grain within two years were $1.82 \mathrm{mg} \mathrm{kg}^{-1}$ and $1.49 \mathrm{mg} \mathrm{kg}^{-1}$, respectively. After the application of insect feces, Cd concentrations in grain decreased by $27.1 \%-63.9 \%$ in 2018 and by $37.9 \%-66.7 \%$ in 2019. During the two-year experiment, $\mathrm{Cd}$ contents in the root were the highest among different parts, which were $20.8 \mathrm{mg} \mathrm{kg}^{-1}$ and $18.2 \mathrm{mg} \mathrm{kg}^{-1}$. After the application of insect feces, $\mathrm{Cd}$ contents in various plant parts considerably decreased by different extents in two years, such as husk (8.3\%-19.9\% and 29.7\%-33.6\%, respectively, for years 2018 and 2019 ), leaf (15.9\%-34.4\% and $38.3 \%-49.8 \%)$, stem (15.0\%-36.0\% and $29.6 \%-43.1 \%$ ) and root (39.7\%-57.5\% and 39.9\%-55.1\%). In 2018, the overall order of Cd content in the above-ground and underground parts of rice under different fertilization treatments was T1 > T4 > T3 > T2; while in 2019, the overall order was changed as T1 > T2 > T3 > T4. Under the same treatment, Cd content in each part of rice in 2019 was lower than that in 2018, especially for the T4 treatment with the largest decline in Cd concentration in each part. Compared with 2018, the contents of Cd in grain, husk, leaf, stem and root under T4 treatment in 2019 were decreased by $51.5 \%, 32.5 \%, 44.5 \%, 29.4 \%$ and $34.5 \%$, respectively.

The effect of insect feces on $\mathrm{Pb}$ contents in each part of rice plant is shown in Fig. 6. The concentration ranges of $\mathrm{Pb}$ in different plant parts were as follows: $0.56-1.44 \mathrm{mg} \mathrm{kg}^{-1}$ in grain, $0.63-1.67 \mathrm{mg} \mathrm{kg}^{-1}$ in husk, $10.0-19.2 \mathrm{mg} \mathrm{kg}^{-1}$ in leaf, $0.78-2.58 \mathrm{mg} \mathrm{kg}^{-1}$ in stem and $559.6-1013.7 \mathrm{mg} \mathrm{kg}^{-1}$ in root. $\mathrm{Pb}$ 
contents of different parts under CK treatment were the highest. After applying insect feces, $\mathrm{Pb}$ concentrations were decreased by $14.6 \%-53.1 \%$ in grain, $16.4 \%-53.5 \%$ in husk, $6.4 \%-36.8 \%$ in leaf, $24.7 \%-61.8 \%$ in stem and $24.4 \%-38.7 \%$ in root. Among all fertilization treatments, $\mathrm{Pb}$ contents in all parts of rice plant under T2 treatment in 2018 were the lowest, while those under T4 treatment in 2019 were the lowest. Compared with 2018, $\mathrm{Pb}$ contents under the same fertilization treatment in 2019 were decreased by $4.1 \%-51.5 \%$ in grain, $20.8 \%-45.6 \%$ in husk, $20.1 \%-42.0 \%$ in leaf, $26.0 \%-54.6 \%$ in stem and $2.5 \%-13.7 \%$ in root. This indicated that the application of insect feces could reduce $\mathrm{Pb}$ accumulation in rice.

\subsection{Effects of insect feces on $\mathrm{Cd}$ and $\mathrm{Pb}$ absorption and transport coefficients of rice}

The values of absorption coefficients and transport coefficients were used to characterize the ability of rice to enrich and transport heavy metals (McGrath and Zhao 2003). Higher absorption coefficients suggest stronger ability of plant to absorb heavy metals, and higher transport coefficients suggest stronger ability of plant root to transport heavy metals to the above-ground parts. The effect of insect feces application on the absorption and transport coefficients of $\mathrm{Cd}$ and $\mathrm{Pb}$ is shown in Table 2. Without insect feces application, the $\mathrm{Cd}$ absorption coefficients were 1.959 and 1.712 in two years, while the $\mathrm{Pb}$ absorption coefficients were 0.739 and 0.624 in two years. The $\mathrm{Cd}$ absorption coefficients were 2.65 and 2.74 times higher than those of $\mathrm{Pb}$ within two years, indicating that rice could absorb $\mathrm{Cd}$ more readily than $\mathrm{Pb}$. The application of insect feces significantly reduced the absorption coefficients of the two heavy metals in rice ( $\mathrm{Cd}$ and $\mathrm{Pb}$ decreased by $39.5 \%-57.5 \%$ and $24.4 \%-38.7 \%$, respectively). For CK treatment, the primary transport coefficients of $\mathrm{Cd}$ were 0.127 and 0.120 within two years, which were 16.1 and 12.2 times higher than those of $\mathrm{Pb}$, respectively. The application of insect feces increased the primary transport coefficients of $\mathrm{Cd}$ and $\mathrm{Pb}$. Moreover, the secondary transport coefficients of $\mathrm{Cd}$ under $\mathrm{CK}$ treatment were 0.690 and 0.684 within two years, and those of $\mathrm{Pb}$ were 0.180 and 0.143 , respectively. Application of insect feces reduced the secondary transport coefficients of $\mathrm{Cd}$ by $7.8-44.1 \%$ and reduced those of $\mathrm{Pb}$ by 3.6-21.6\%. Among different treatments, the absorption coefficients of $\mathrm{Cd}$ and $\mathrm{Pb}$ and the secondary transport coefficients of Cd under T2 and T3 treatments in 2018 were significantly lower than those under $\mathrm{T} 1$ treatment; while in 2019, the absorption coefficients and secondary transport coefficients of $\mathrm{Cd}$ and $\mathrm{Pb}$ under $\mathrm{T} 4$ treatment were significantly lower than those under $\mathrm{T} 1$ treatment. This indicated that the insect feces application reduced the uptake of $\mathrm{Cd}$ and $\mathrm{Pb}$ from soil by rice plant and decreased the metal migration from stem and leaf to grain, but enhanced the migration of $\mathrm{Cd}$ and $\mathrm{Pb}$ from root to stem and leaf.

The absorption coefficients of $\mathrm{Cd}$ and $\mathrm{Pb}$ were the highest, followed by the secondary transport coefficients, and the primary transport coefficients were the lowest (Table 2). For example, the absorption coefficients of Cd were 2.1 times and 7.4 times of the secondary and primary transport coefficients on average, respectively, and the absorption coefficients of $\mathrm{Pb}$ were 3.4 times and 52.7 times of the secondary and primary transport coefficients, respectively. This suggested that the absorption and accumulation capacities of soil heavy metals by rice root were much greater than those of above-ground part. 
Table 2

$\mathrm{Cd}$ and $\mathrm{Pb}$ absorption and transport coefficients of rice before and after application of insect feces

\begin{tabular}{|c|c|c|c|c|c|c|c|}
\hline & \multirow[t]{2}{*}{ Treatment } & \multicolumn{2}{|c|}{ Absorption coefficients } & \multicolumn{2}{|c|}{$\begin{array}{l}\text { Primary transport } \\
\text { coefficients }\end{array}$} & \multicolumn{2}{|c|}{$\begin{array}{l}\text { Secondary transport } \\
\text { coefficients }\end{array}$} \\
\hline & & 2018 & 2019 & 2018 & 2019 & 2018 & 2019 \\
\hline \multirow[t]{5}{*}{$\mathrm{Cd}$} & CK & $\begin{array}{l}1.959 \pm \\
0.044 \mathrm{a}\end{array}$ & $\begin{array}{l}1.712 \pm \\
0.066 \mathrm{a}\end{array}$ & $\begin{array}{l}0.127 \pm \\
0.001 \mathrm{c}\end{array}$ & $\begin{array}{l}0.120 \pm \\
0.002 \mathrm{c}\end{array}$ & $\begin{array}{l}0.690 \pm \\
0.029 \mathrm{a}\end{array}$ & $\begin{array}{l}0.684 \pm \\
0.040 \mathrm{a}\end{array}$ \\
\hline & T1 & $\begin{array}{l}1.182 \pm \\
0.092 \mathrm{~b}\end{array}$ & $\begin{array}{l}1.029 \pm \\
0.013 \mathrm{~b}\end{array}$ & $\begin{array}{l}0.179 \pm \\
0.019 a\end{array}$ & $\begin{array}{l}0.135 \pm \\
0.008 \mathrm{~b}\end{array}$ & $\begin{array}{l}0.594 \pm \\
0.048 \mathrm{~b}\end{array}$ & $\begin{array}{l}0.631 \pm \\
0.036 \mathrm{a}\end{array}$ \\
\hline & T2 & $\begin{array}{l}0.832 \pm \\
0.009 \mathrm{c}\end{array}$ & $\begin{array}{l}0.913 \pm \\
0.010 \mathrm{c}\end{array}$ & $\begin{array}{l}0.192 \pm \\
0.006 \mathrm{a}\end{array}$ & $\begin{array}{l}0.139 \pm \\
0.000 \mathrm{ab}\end{array}$ & $\begin{array}{l}0.386 \pm \\
0.036 \mathrm{c}\end{array}$ & $\begin{array}{l}0.469 \pm \\
0.025 \mathrm{~b}\end{array}$ \\
\hline & T3 & $\begin{array}{l}0.909 \pm \\
0.027 \mathrm{c}\end{array}$ & $\begin{array}{l}0.789 \pm \\
0.025 d\end{array}$ & $\begin{array}{l}0.183 \pm \\
0.003 \mathrm{a}\end{array}$ & $\begin{array}{l}0.145 \pm \\
0.002 \mathrm{a}\end{array}$ & $\begin{array}{l}0.446 \pm \\
0.018 \mathrm{c}\end{array}$ & $\begin{array}{l}0.447 \pm \\
0.026 \mathrm{~b}\end{array}$ \\
\hline & T4 & $\begin{array}{l}1.174 \pm \\
0.071 \mathrm{~b}\end{array}$ & $\begin{array}{l}0.769 \pm \\
0.018 \mathrm{~d}\end{array}$ & $\begin{array}{l}0.150 \pm \\
0.011 \mathrm{~b}\end{array}$ & $\begin{array}{l}0.145 \pm \\
0.003 \mathrm{a}\end{array}$ & $\begin{array}{l}0.551 \pm \\
0.051 \mathrm{~b}\end{array}$ & $\begin{array}{l}0.421 \pm \\
0.015 \mathrm{~b}\end{array}$ \\
\hline \multirow[t]{5}{*}{$\mathrm{Pb}$} & CK & $\begin{array}{l}0.739 \pm \\
0.040 a\end{array}$ & $\begin{array}{l}0.624 \pm \\
0.021 \mathrm{a}\end{array}$ & $\begin{array}{l}0.0079 \pm \\
0.0005 \mathrm{c}\end{array}$ & $\begin{array}{l}0.0098 \pm \\
0.0005 \mathrm{~b}\end{array}$ & $\begin{array}{l}0.180 \pm \\
0.014 \mathrm{a}\end{array}$ & $\begin{array}{l}0.143 \pm \\
0.010 \mathrm{a}\end{array}$ \\
\hline & T1 & $\begin{array}{l}0.525 \pm \\
0.034 \mathrm{~b}\end{array}$ & $\begin{array}{l}0.472 \pm \\
0.020 \mathrm{~b}\end{array}$ & $\begin{array}{l}0.0099 \pm \\
0.0008 \mathrm{ab}\end{array}$ & $\begin{array}{l}0.0105 \pm \\
0.0004 a\end{array}$ & $\begin{array}{l}0.174 \pm \\
0.013 \mathrm{ab}\end{array}$ & $\begin{array}{l}0.134 \pm \\
0.006 \mathrm{a}\end{array}$ \\
\hline & T2 & $\begin{array}{l}0.453 \pm \\
0.031 \mathrm{c}\end{array}$ & $\begin{array}{l}0.442 \pm \\
0.015 \mathrm{bc}\end{array}$ & $\begin{array}{l}0.0091 \pm \\
0.0001 \mathrm{~b}\end{array}$ & $\begin{array}{l}0.0098 \pm \\
0.0000 \mathrm{ab}\end{array}$ & $\begin{array}{l}0.153 \pm \\
0.006 \mathrm{~b}\end{array}$ & $\begin{array}{l}0.126 \pm \\
0.018 \mathrm{a}\end{array}$ \\
\hline & T3 & $\begin{array}{l}0.465 \pm \\
0.011 \mathrm{c}\end{array}$ & $\begin{array}{l}0.425 \pm \\
0.038 \mathrm{bc}\end{array}$ & $\begin{array}{l}0.0089 \pm \\
0.0003 \mathrm{~b}\end{array}$ & $\begin{array}{l}0.0099 \pm \\
0.0012 \mathrm{ab}\end{array}$ & $\begin{array}{l}0.164 \pm \\
0.013 \mathrm{ab}\end{array}$ & $\begin{array}{l}0.133 \pm \\
0.009 \mathrm{ab}\end{array}$ \\
\hline & T4 & $\begin{array}{l}0.473 \pm \\
0.017 \mathrm{bc}\end{array}$ & $\begin{array}{l}0.408 \pm \\
0.024 \mathrm{c}\end{array}$ & $\begin{array}{l}0.0106 \pm \\
0.0005 a\end{array}$ & $\begin{array}{l}0.0090 \pm \\
0.0004 b\end{array}$ & $\begin{array}{l}0.154 \pm \\
0.010 \mathrm{~b}\end{array}$ & $\begin{array}{l}0.112 \pm \\
0.008 \mathrm{~b}\end{array}$ \\
\hline
\end{tabular}

\section{Discussion}

The black soldier fly larvae feces become a new type of biological organic fertilizer, which contain not only a variety of nutrients, but also diversified microorganisms, enzymes and active substances (Liu et al. 2019a; Wu et al. 2019). The insect feces used in this study contained high contents of OM (64\%) and nutrients (sum of $\mathrm{N}, \mathrm{P}$ and $\mathrm{K}$ was $11.5 \%$ ), which were far higher than those in the commercial organic fertilizer standards of China (NY525-2012) (OM $\geq 45 \%, N+P+K \geq 5 \%)$. Most of the nutrients in organic fertilizers exist as organic forms and are released during the mineralization process of organic matters, so the effect on soil fertility is slow and long (Li et al. 2017). Here, the application of insect feces significantly increased the contents of soil OM and nitrogen, phosphorus and potassium nutrients within two years. The increase of available nutrient contents provided more nutrients for the rice growth and promoted the rice yield. Meanwhile, the increase of available phosphorus content could also fix heavy metal ions and reduced the damage to crops. In the first year of planting, the rice yield was the highest when $4 \%$ of insect feces was applied, while the yields under $6 \%$ and $8 \%$ of insect feces applied were 
reduced. In particular, the yield of $8 \%$ treatment was significantly lower than that of the control without fertilization. This might be because the application amount was too large and the mineralization of insect feces in flooded soil produced a large amount of methane, hydrogen sulfide and other harmful gases (Wu et al. 2011). At the same time, the oxygen in the soil was consumed, which inhibited the growth and development of rice roots, resulting in the decrease of crop yield. On the other hand, the overuse of organic fertilizer may lead to excessive soil nutrients, resulting in a decreased yield (Namba 2003; Xia and Yan 2011). In the second year, the rice yield elevated with the increase of insect feces amounts. The rice yields treated with $6 \%$ and $8 \%$ insect feces were significantly higher than those of other treatments and also higher than those of the first year. This indicated that insect feces had a remarkably successive fertilization effect and could provide a large amount of nutrients for rice growth in the second year.

The morphology of heavy metals in soil is an important factor in determining their bioavailability (Hou et al. 2014; Song et al. 2013). For example, heavy metals in the weak acid soluble state are easy to be absorbed and utilized by crops, and are also sensitive to changes in environmental conditions; while heavy metals in the oxidizable and residual states have the weakest toxic effects on soil and crops due to their low bioavailabilities (Zhang 2017). In this study, the application of insect feces reduced the contents of weak acid soluble $\mathrm{Cd}$ and $\mathrm{Pb}$ in soil, but increased those of oxidizable and residual states. This finding is consistent with the conclusions of most studies that applying organic fertilizers could decrease metal availability in soil to passivate metals (Alvarenga et al. 2009; Susan et al. 2009).

The heavy metal speciations in soil vary with the change in soil pH, OM and Eh ( $\mathrm{Ma}$ et al. 2019). The application of insect feces improved the soil $\mathrm{pH}$ and $\mathrm{OM}$ contents, which could further reduce metal availability in contaminated soil and hinder the metal migration from soil to rice. Specifically, the rise of soil pH increases the adsorption positions of heavy metals and the stability of adsorption surface, and changes the speciation of heavy metal ions and ligand properties. This will further accelerate the transformation of metal speciation into organic binding and residue states and reduce the heavy metal availability (Liu et al. 2019b; Yang et al. 2014). In addition, the insect feces have high OM contents and a large number of active functional groups as well as high specific surface area, resulting in their adsorption capacities of metal ions far beyond other mineral colloids. Organic compounds and their decomposition products e.g., humic acid, can act as ligands to form organic metal complexes with heavy metal ions in soil, thus affecting the metal availability (Liu and Wang 2007). Moreover, the application of insect feces could strengthen the oxidation reduction effects of soil under flooding conditions and reduce soil Eh values. New iron oxides are generated when the original iron oxides are reduced and dissolved. The amorphous or microcrystalline structures of the newly formed iron oxides can absorb a large quantity of heavy metal ions or ion groups in the solution, resulting in a decrease in metal bioavailability (Kashem and Singh 2004; Tack et al. 2006; Wang et al. 2016). The reduction of the available heavy metals in soil decreased the sources of the heavy metals that could be absorbed by rice as well as the metal accumulation in various parts of rice. For example, the metal availability of $\mathrm{Cd}$ and $\mathrm{Pb}$ in soil decreased after application of insect feces, which might be the reason why fertilization reduced the accumulation of $\mathrm{Cd}$ and $\mathrm{Pb}$ in rice (Fig. 5-6). 
The application of insect feces reduced the absorption coefficients and secondary transfer coefficients of $\mathrm{Cd}$ and $\mathrm{Pb}$ by rice, and inhibited the absorption and migration of heavy metals to rice grains. Although the insect feces application promoted the transfer of $\mathrm{Cd}$ and $\mathrm{Pb}$ from root to stem and leaf, the absorption coefficients of root were much greater than the primary transfer coefficients from root to stem and leaf (Table 2). Thus, the overall performance of applying insect feces was still to reduce the absorption and accumulation of heavy metals in crops, which is similar to the results of Zhang et al. (2020). In 2019, the contents of $\mathrm{Cd}$ and $\mathrm{Pb}$ in each part of rice decreased with the rise of the application amount of insect feces, which was consistent with the previous research (Li et al. 2020b; Xiao et al. 2017). In 2018, the Cd and $\mathrm{Pb}$ contents in each part of rice treated with $4 \%$ insect feces were the lowest, while those treated with $6 \%$ and $8 \%$ insect feces were elevated. This was possibly because the biomass of rice treated with $4 \%$ insect feces was the highest and had a dilution effect.

The $\mathrm{Cd}$ and $\mathrm{Pb}$ contents in rice in the first year are higher than those in the second year. This might be attributed to that the activities of $\mathrm{Cd}$ and $\mathrm{Pb}$ in soil had not yet reached stable states and were relatively high during the first year of rice cultivation process. In this study, the soil balance aging time was relatively short ( $30 \mathrm{~d}$ ) before planting, while related research has shown that the aging time for $\mathrm{Cd}$ and $\mathrm{Pb}$ in soil was about 60-90 days (Cai et al. 2019; Zhang et al. 2019). At the same time, more humus was formed with the mineralization of insect feces in the second year, which might also reduce the contents of bioavailable $\mathrm{Cd}$ and $\mathrm{Pb}$.

\section{Conclusions}

The application of insect feces remarkably increased the contents of soil $\mathrm{pH}, \mathrm{EC}, \mathrm{OM}$, ammonium nitrogen, available phosphorus and potassium. Meanwhile, the insect feces application reduced the concentrations of $\mathrm{Cd}$ and $\mathrm{Pb}$ in the weak acid-soluble state in soil, but increased those in the oxidizable and residual states. This effect became more evident with the increase of the application amount of insect feces. Except for the T4 treatment in the first year, all fertilization treatments increased the rice yield (up to $43.7 \%$ and $195.5 \%$ higher than those of CK in two years). Moreover, the application of insect feces decreased the absorption coefficients of $\mathrm{Cd}$ and $\mathrm{Pb}$ by the rice root system, the metal transport coefficients from the stem and leaf to the grain, as well as the accumulative metal concentrations in various parts of rice plant. The insect feces application can not only improve soil fertility and rice yield, but also reduce the soil metal activities and inhibit their transfer to rice. These results could provide a theoretical basis for the rational application of insect feces as organic fertilizers and for the remediation of heavy metal contaminated soil.

\section{Declarations}

Authors' contributions All authors contributed to the study conception and design. X.B. Wang: conceptualization, writing-original draft preparation; $\mathrm{N}$. Wu: visualization, writing-review and editing; $\mathrm{X}$. Wu: methodology, data curation; W.N. Geng: writing-review and editing; X.Y. Xu: supervision, funding acquisition. All authors read and approved the final manuscript. 
Funding This work was supported by the National Key Research and Development Program of China (2018YFD0500205), Tianjin Science and Technology Plan Project (19ZYYFSN00010, 18ZXYENC00130), and National Natural Science Foundation of China (21607114).

Data availability The datasets used and/or analyzed during the current study are available from the corresponding author on reasonable request.

\section{Compliance with ethical standards}

Ethical approval and consent to participate Not applicable

Consent to publish Not applicable

Competing interests The authors declare that they have no competing interests.

\section{References}

1. Alvarenga P, Palma P, Gonqalves AP, Fernandes RM, Varennes AD, Vallini G, Duarte E, Cunha-Queda AC (2009) Organic residues as immobilizing agents in aided phytostabilization: (II) Effects on soil biochemical and ecotoxicological characteristics. Chemosphere 74:1301-1308

2. Bao SD (2000) Soil and agricultural chemistry analysis. China Agriculture Press China Agriculture Press, Beijing, pp 178-200

3. Cai Q, Xu Q, Zhou Z (2019) Aging process of Pb affects the chemical properties of four types of soil. Acta Sci Circum 39:899-907. doi:10.13671/j.hjkxxb.2018.0376 (in Chinese)

4. Carbonell-Barrachina AA, Burló-Carbonell F, Mataix-Beneyto J (1997) Arsenic uptake, distribution, and accumulation in bean plants: Effect of Arsenite and salinity on plant growth and yield. J Plant Nutr $20: 1419-1430$

5. Chen Q (2018) Study on the damage of environmental heavy metal pollution and environmental remediation. Environ Develop 30:52-54. doi:10.16647/j.cnki.cn15-1369/X.2018.08.032 (in Chinese)

6. Chen W, Yang Y, Xie A (2018) Challenges and countermeasures for the prevention and control of heavy metal pollution in farmland in China. Acta Pedol Sin 55:261-272 (in Chinese)

7. Fellet G, Marchiol L, Delle Vedove G, Peressotti A (2011) Application of biochar on mine tailings: effects and perspectives for land reclamation. Chemosphere 83:1262-1267

8. Hou Y, Zhao L, Meng H, Shen Y, Cheng H (2014) Passivating effect of biochar and humic acid materials on heavy metals during composting of pig manure. Trans CSAE 30:205-215. doi:10.3969/j.issn.1002-6819.2014.11.026

9. Kashem M, Singh B (2004) Transformations in solid phase species of metals as affected by flooding and organic matter. Commun Soil Sci Plant Anal 35:1435-1456

10. Li L, Zhang Y, Ippolito AJ, Xing W, Qiu K, Yang H (2020a) Lead smelting effects heavy metal concentrations in soils, wheat, and potentially humans. Environ Pollut 257:113641 
11. Li W, Zhou W, Yang S (2016) Effect of insect sand on growth performance of Chinese cabbage. J Anhui Agri Sci 44:111-112. doi:10.13989/j.cnki.0517-6611.2016.10.037 (in Chinese)

12. Li Y, He X, Wang Y, Guan J, Guo J, Xu B, Chen Y, Wang G (2020b) Organic fertilizer amendment increases methylmercury accumulation in rice plants. Chemosphere 249:126166

13. Li Y, Zhao B, Li Z (2017) Research progress of organic and inorganic combined fertilization system. J Agri 7:22-30 (in Chinese)

14. Liu C, Wang C, Yao H (2019a) Comprehensive Resource Utilization of Waste Using the Black Soldier Fly (Hermetia illucens (L.)) (Diptera: Stratiomyidae). Animals 9:349

15. Liu H, Wang L (2007) The application of nonmetallic minerals in soil environmental protection is emphasized. China Min Mag 8:71-73 (in Chinese)

16. Liu Y, Liu Y, Zhu G (2019b) Effects of lime on the chemical morphology of heavy metals in $\mathrm{Cu}, \mathrm{Cd}, \mathrm{Pb}$ and Zn contaminated soil. Environ Eng 37:158-164 (in Chinese)

17. Ma L, Sun Y, Xu Z (2019) Analysis on soil heavy metal morphology transformation and soil pollution treatment. Environ Impact Assess 5:18-21. doi:10.14068/j.ceia.2019.05.004 (in Chinese)

18. McGrath SP, Zhao FJ (2003) Phytoextraction of metals and metalloids from contaminated soils. Curr Opin Biotech 14:277-282

19. Meng J, Tao M, Wang L, Liu X, Xu J (2018) Changes in heavy metal bioavailability and speciation from a $\mathrm{Pb}-\mathrm{Zn}$ mining soil amended with biochars from co-pyrolysis of rice straw and swine manure. Sci Total Environ 633:300-307

20. Namba T (2003) Optimum planting density and nitrogen application rate for maximizing rice yield in the Nile Delta. Jpn J Crop Sci 72:133-141

21. Newton L, Sheppard D, Watson D, Burtle G, Dove C, Tomberlin J, Thelen E (2005) The black soldier fly, Hermetia illucens, as a manure management/resource recovery tool. North Carolina State University

22. Song C, Wei Z, Xi B, Li M, Xia X, He X, Wan S (2013) Influence of co-composting treatment of anaerobic digested residue on the morphological variation of heavy metals. J Safe Environ 13:62-66 (in Chinese)

23. Susan T, R HJ, A NM (2009) Remediation of metal polluted mine soil with compost: co-composting versus incorporation. Environ Pollut 157:690-697

24. Tack F, Van Ranst E, Lievens C, Vandenberghe R (2006) Soil solution Cd, Cu and Zn concentrations as affected by short-time drying or wetting: The role of hydrous oxides of Fe and Mn. Geoderma 137:83-89

25. Tang X, Li X, Liu X, Hashmi MZ, Xu J, Brookes PC (2015) Effects of inorganic and organic amendments on the uptake of lead and trace elements by Brassica chinensis grown in an acidic red soil. Chemosphere 119:177-183

26. Tian X, Li T, Yang K, Xu Y, Lu H, Lin D (2012) Effect of humic acids on physicochemical property and $\mathrm{Cd}$ (II) sorption of multiwalled carbon nanotubes. Chemosphere 89:1316-1322 
27. Udovic M, McBride MB (2012) Influence of compost addition on lead and arsenic bioavailability in reclaimed orchard soil assessed using Porcellio scaberbioaccumulation test. J Hazard Mater 205206:144-149

28. Wang R, Guo J, Xu Y, Ding Y, Shen Y, Zheng X, Feng R (2016) Evaluation of silkworm excrement and mushroom dreg for the remediation of multiple heavy metal/metalloid contaminated soil using pakchoi. Ecotox Environ Safe 124:239-247

29. Wang X, Wu N, Cai R, Geng W, Xu X (2020) Changes in speciation, mobility and bioavailability of Cd, $\mathrm{Cr}$ and As during the transformation process of pig manure by black soldier fly larvae (Hermetia illucens). J Integr Agr (in press). doi:10.1016/S2095-3119(20)63333-0

30. Wang Z, Qin H, Wang J (2019) Accumulation of uranium and heavy metals in the soil-plant system in Xiazhuang uranium ore field, Guangdong Province, China. Environ Geochem HIth 41:2413-2423

31. Wu J, Ji X, Peng H (2011) Effects of different types of organic fertilizers on $\mathrm{CH}_{4}$ emission in one crop rice field. J Agro-Environ Sci 30:1688-1694 (in Chinese)

32. Wu X, Hu C, Cai R (2019) Effects of insect manure on the growth and quality of tomato. Northern Hort 3:60-64 (in Chinese)

33. Xia Y, Yan X (2011) Ecologically optimal nitrogen application rates for rice cropping in the Taihu Lake region of China. Sustain Sci 7:33-44

34. Xiao A, Ouyang Y, Li WC, Ye Z (2017) Effect of organic manure on Cd and As accumulation in brown rice and grain yield in Cd-As-contaminated paddy fields. Environ Sci Pollut Res 24:9111-9121

35. Yang F, Ding K, Liu T (2014) Research progress on the factors affecting the chemical transformation of heavy metals in soil. J Anhui Agri Sci 42:10083-10084. doi:10.13989/j.cnki.05176611.2014 .29 .015 (in Chinese)

36. Zhang F, Zhao Y, Ma X (2019) Aging characteristics of Cd and Ni in soil based on DGT technology. J Agro-Environ Sci 38:2487-2495 (in Chinese)

37. Zhang L (2017) Study on biochar remediation of Cd contamination in acid paddy soil. Northeast agricultural university (in Chinese)

38. Zhang Q, Wang H, Kong Q (2020) Effects of superfine phosphate rock powders on $\mathrm{Pb}$ and $\mathrm{Cd}$ uptake and transportation in rice at different growth stages. J Agro-Environ Sci 39:45-54 (in Chinese)

\section{Figures}



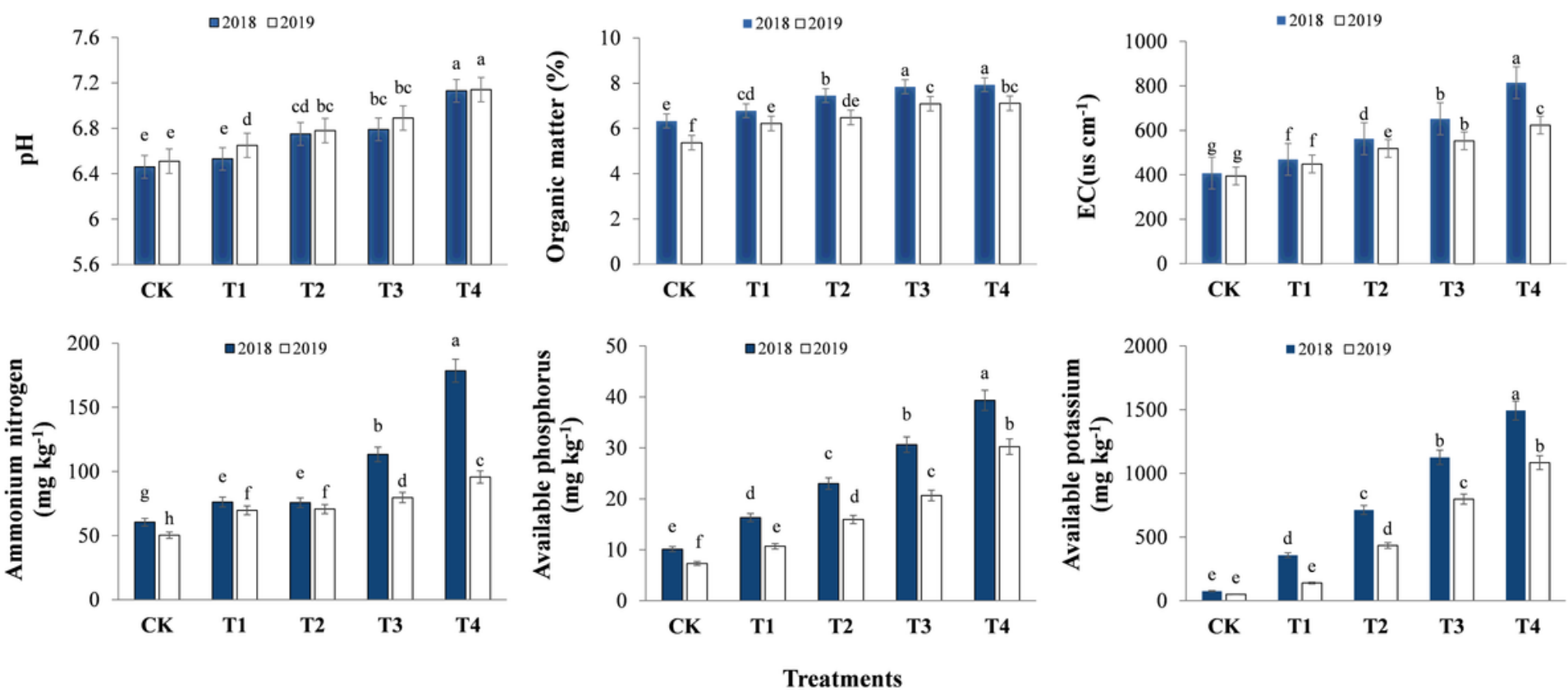

Figure 1

Effects of different amounts of insect feces on soil physicochemical properties within two years.

$\because \mathrm{F} 1 \quad \mathrm{~F} 2 \quad \mathrm{~F} 3 \quad \mathrm{~F} 4$

$\because \mathrm{F} 1 \backsim \mathrm{F} 2 \square \mathrm{F} 3 \square \mathrm{F} 4$

Uే

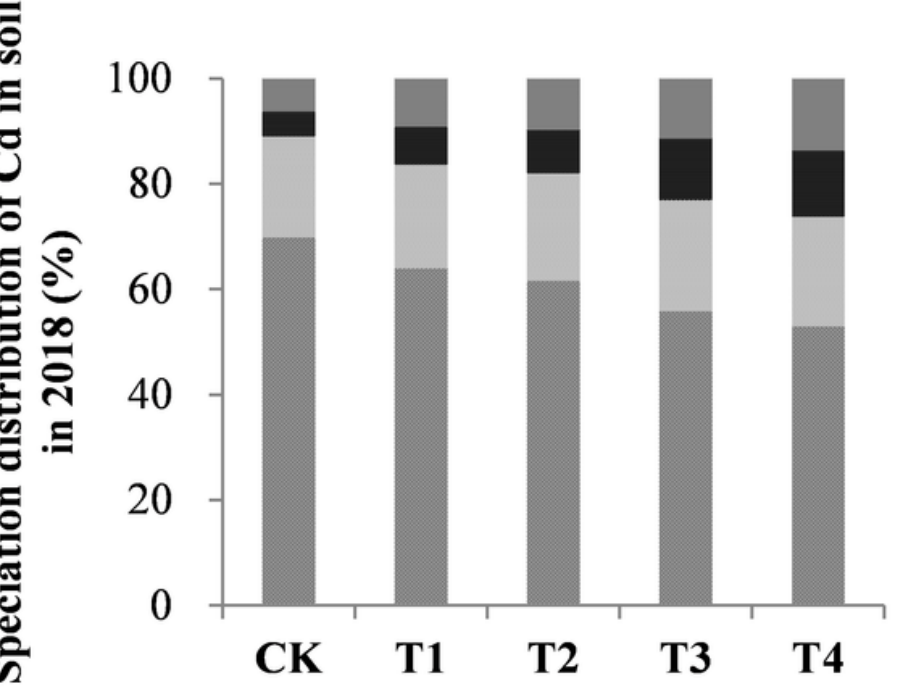

Treatments

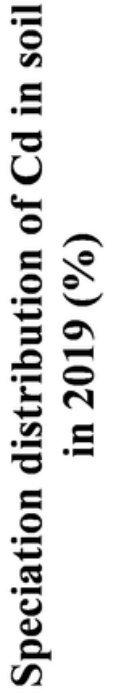

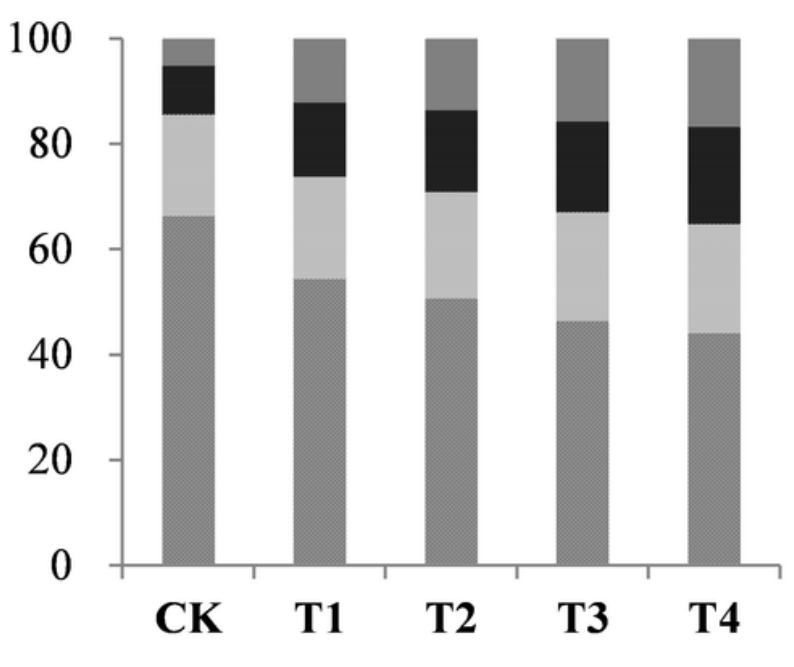

Treatments

\section{Figure 2}

Influence of different amounts of insect feces on the changes of soil Cd speciation within two years. F1: weak acid soluble fraction; F2: reducible fraction; F3: oxidizable fraction; F4: residual fraction. 
$\because \mathrm{F} 1 \backsim \mathrm{F} 2 \quad \mathrm{~F} 3 \quad \mathrm{~F} 4$

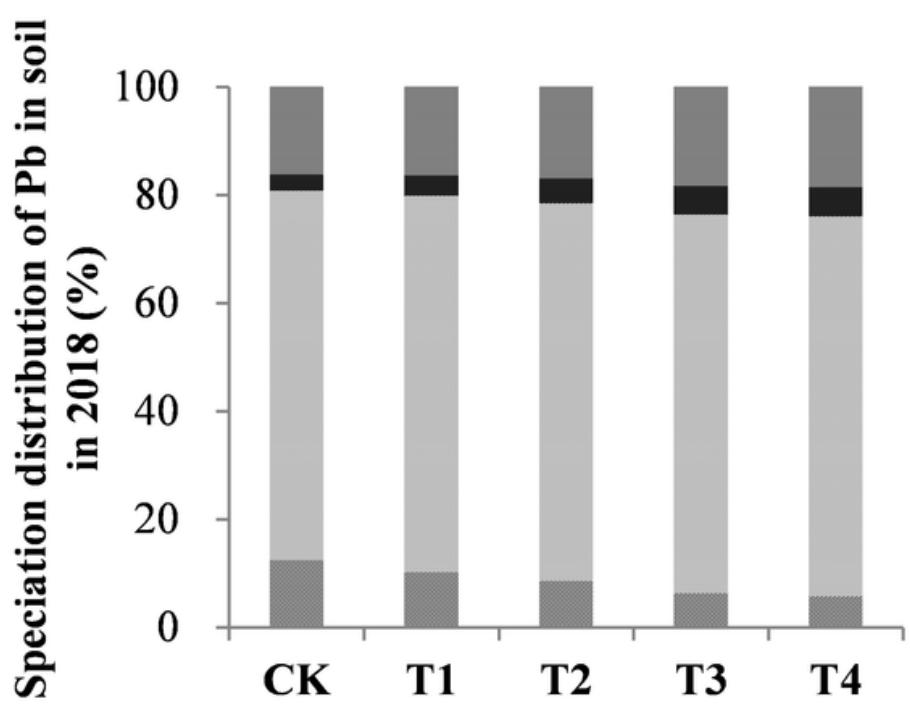

Treatments $\because \mathrm{F} 1 \square \mathrm{F} 2 \square \mathrm{F} 3 \quad \square \mathrm{F} 4$

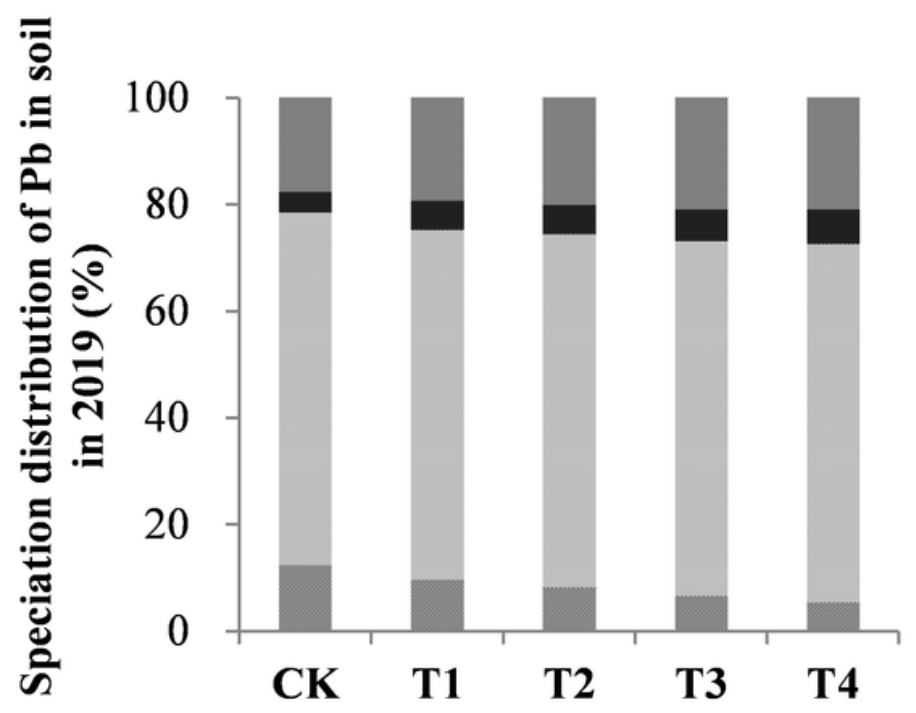

Figure 3

Influence of different amounts of insect feces on the changes of soil Pb speciation within two years. F1: weak acid soluble fraction; F2: reducible fraction; F3: oxidizable fraction; F4: residual fraction. 


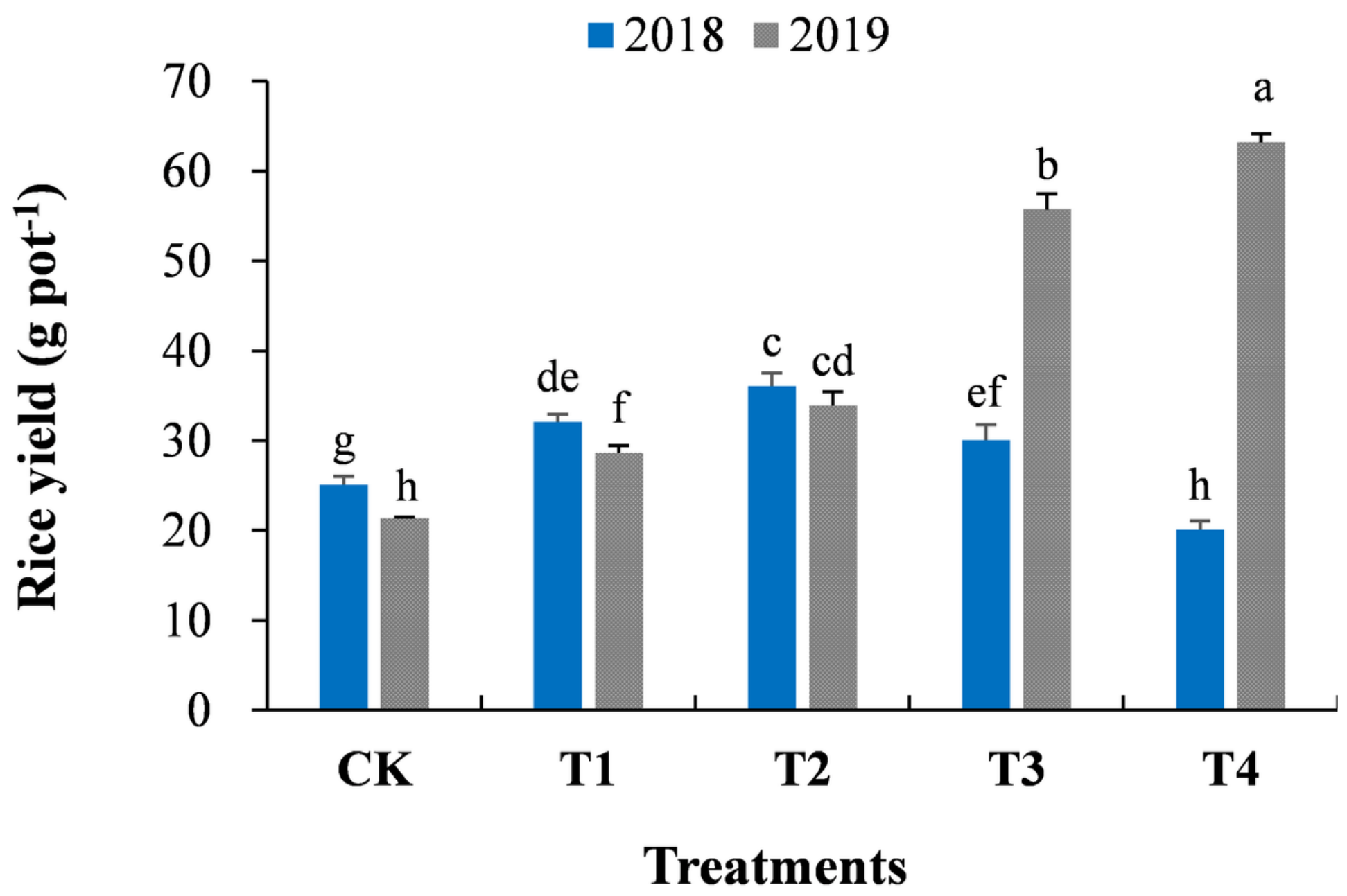

Figure 4

Effects of different amounts of insect feces on rice yield within two years. Different letters indicated significant difference $(P<0.05)$. 

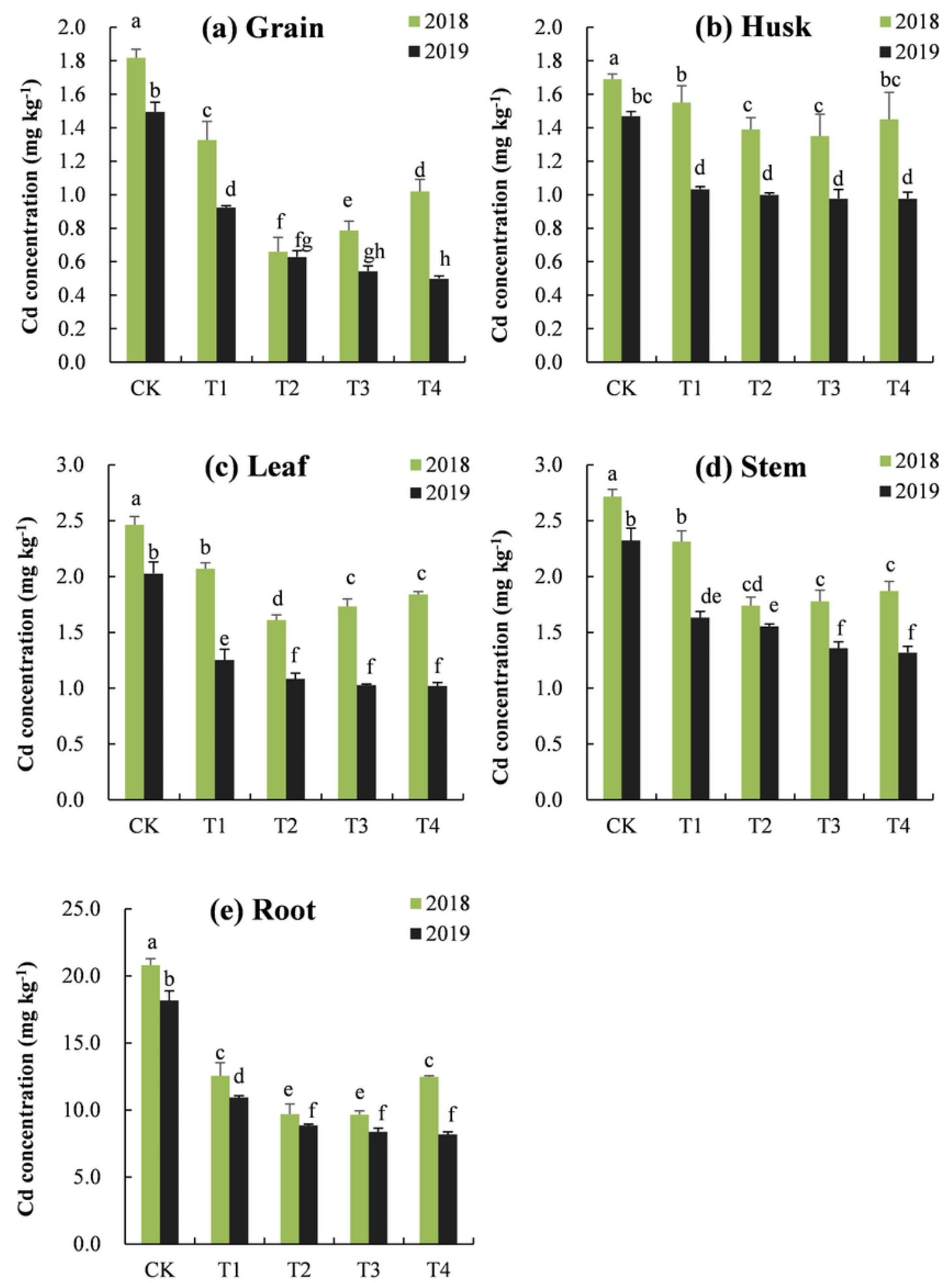

Figure 5

Effects of different amounts of insect feces on Cd contents in various parts of rice plant. 

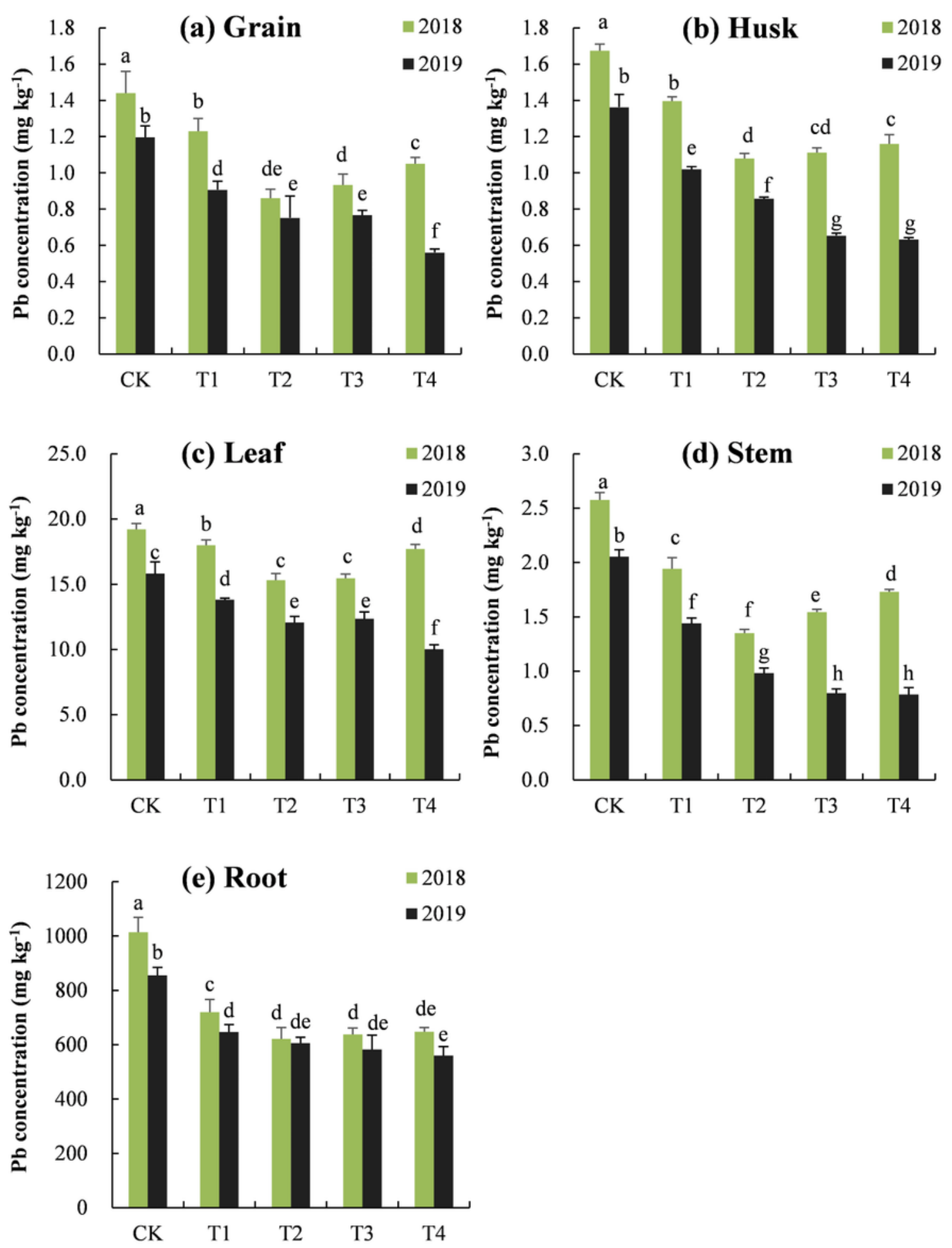

Figure 6

Effects of different amounts of insect feces on $\mathrm{Pb}$ contents in various parts of rice plant. 